CARDIOVASCULAR MEDICINE

\title{
Prevalence and clinical significance of systolic impairment in hypertrophic cardiomyopathy
}

\author{
R Thaman, J R Gimeno, R T Murphy, T Kubo, B Sachdev, J Mogensen, P M Elliott, W J McKenna
}

Heart 2005;91:920-925. doi: 10.1136/hrt.2003.031161

See end of article for authors' affiliations

Correspondence to: Dr Perry M Elliott, The Heart Hospital, 16-18 Westmoreland Street London WIG 8PH, UKK perry.elliott@uclh.org

Accepted 24 May 2004
Objectives: To determine the frequency of systolic impairment (SI) and its impact on the natural history of hypertrophic cardiomyopathy (HCM).

Methods: 1080 patients (mean (SD) age 43 (15) years, 660 men) with HCM were evaluated. Initial assessment included history, examination, 48 hour Holter monitoring, cardiopulmonary exercise testing, and echocardiography; SI was defined as a fractional shortening (FS) $\leqslant 25 \%$. Survival data were collected at clinic visits or by direct communication with patients and their general practitioners. The results of serial echocardiography in 462 patients with normal FS at presentation are also reported.

Results: 26 (2.4\%) patients (49 (14) years, 18 men) had SI at the initial visit. During follow up (58 (49) months), nine $(34.6 \%)$ died or underwent cardiac transplantation compared with $108(10.2 \%)$ patients with normal FS $(p=0.01)$. Five year survival from death (any cause) or transplantation was $90.1 \% 195 \%$ confidence interval (Cl) 87.8 to 92.4$)$ in patients with normal systolic function versus $52.4 \%(95 \% \mathrm{Cl} 25.2$ to $79.6, \mathrm{p}<0.0001)$ in patients with SI. In patients who underwent serial echocardiography, 22 (4.8\%, aged 41 (15) years) developed SI over 66 (40) months; the annual incidence of SI was $0.87 \%(95 \% \mathrm{CI}$ 0.54 to 1.31). On initial evaluation patients who developed SI had a higher frequency of syncope (67 $(15.2 \%)$ v $10(45.5 \%)$ of those who did not develop SI, $\mathrm{p}=0.001)$, non-sustained ventricular tachycardia (91 $(20.6 \%) \vee 11(50 \%), p=0.002)$, and an abnormal blood pressure response on exercise (131 $(29.7 \%)$ v $15(68.2 \%), p=0.001)$. Patients with SI had greater wall thinning ( $p=0.001$ ), left ventricular cavity enlargement ( $p<0.0005)$, and deterioration in New York Heart Association functional class ( $p=0.001$ ) during follow up. Thirteen $(59.1 \%)$ patients who progressed to SI died or underwent transplantation compared with $38(8.6 \%)$ patients who maintained normal systolic function.

Conclusions: $\mathrm{SI}$ is an infrequent complication of HCM but, when present, is associated with a poor prognosis.
A lthough it is well recognised that some patients with hypertrophic cardiomyopathy (HCM) progress to an end stage or "burnout" phase resembling dilated cardiomyopathy, the incidence and prevalence of systolic dysfunction and its clinical consequences remain uncertain. ${ }^{1-}$ ${ }^{4}$ The objectives of this study were to determine the frequency of systolic impairment (SI) in a large consecutively referred population of patients with HCM and to evaluate its impact on the natural history of the disease.

\section{METHODS \\ Patients}

The study cohort comprised 1080 consecutively referred adult patients ( $\geqslant 16$ years of age, mean age 43 (15) years, male to female ratio 660:420, from 892 families) assessed at St George's Hospital, London, between 1988 and 2002. The diagnosis of HCM was based on the echocardiographic evidence of left ventricular hypertrophy more than 2 SD for age and sex or in accordance with criteria for the diagnosis of familial disease in patients with at least one first degree relative who has an unequivocal diagnosis. ${ }^{5}$ Patients with other cardiac or systemic diseases that can produce hypertrophy were excluded.

\section{Clinical evaluation}

Initial evaluation included history, clinical examination, 12 lead ECG, echocardiography, 48 hour ambulatory Holter analysis, and symptom limited cardiopulmonary exercise testing with measurement of blood pressure response. All patients underwent risk stratification in accordance with published protocols. ${ }^{78}$ Non-sustained ventricular tachycardia (defined as one or more runs of three or more consecutive ventricular extrasystoles at a rate of more than 120 beats/ min, lasting for less than 30 seconds), abnormal blood pressure response during upright exercise (failure of systolic blood pressure to rise by more than $25 \mathrm{~mm} \mathrm{Hg}$ from baseline values or a fall of more than $10 \mathrm{~mm} \mathrm{Hg}$ from the maximum blood pressure during upright exercise in patients under the age of 40 years), family history of sudden cardiac death, severe left ventricular hypertrophy (maximum left ventricular wall thickness (MLVWT) $\geqslant 30 \mathrm{~mm}$ ), and a history of unexplained syncope were considered risk markers for sudden cardiac death. ${ }^{78}$ Survival data and clinical status were collected at subsequent clinic visits for patients followed up at this institution and by direct communication with patients and their general practitioners when followed up elsewhere.

Seven hundred and forty four (69\%) of the 1080 patients underwent serial echocardiography at least one year apart at St George's Hospital to study changes in systolic function over time. Patients with SI at first evaluation $(\mathrm{n}=26)$, patients who underwent myectomy $(n=21)$, alcohol septal ablation ( $n=14)$, or mitral valve replacement $(n=5)$, and patients who had less than 12 months of follow up

Abbreviations: $\mathrm{Cl}$, confidence interval; $\mathrm{FS}$, fractional shortening; $\mathrm{HCM}$, hypertrophic cardiomyopathy; ICD, implantable cardioverterdefibrillator; LVEDD, left ventricular end diastolic diameter; LVESD, left ventricular end systolic diameter; LVOTG, left ventricular outflow tract gradient; MLVWT, maximum left ventricular wall thickness; NYHA, New York Heart Association; SI, systolic impairment 
( $\mathrm{n}=183$ ) or where follow up videos were unobtainable $(n=23)$ were excluded. Patients with typical angina or risk factors for coronary artery disease during the course of follow up underwent coronary arteriography and 10 patients with coronary disease were also subsequently excluded. The results of the remaining 462 patients (mean (SD) age 41 (14) years, male to female ratio 290:172) are reported.

\section{Echocardiography}

Echocardiography was performed with an Acuson $128 \mathrm{XP} / 10$ (Mountain View, California, USA), GE Vingmed system V (GE Ultrasound Europe, Horten, Norway), or a Hewlett Packard Sonos 1000 (Hewlett Packard, Andover, Massachusetts, USA). Standard views for M mode and two dimensional studies were obtained. Left ventricular end diastolic (LVEDD) and left ventricular end systolic diameters (LVESD) were measured from two dimensional and M mode images obtained from parasternal long axis views. Fractional shortening (FS) was calculated by the formula $(($ LVEDD - LVESD $) /$ LVEDD $) \times 100$ and SI was defined as FS $\leqslant 25 \%$. The magnitude and distribution of left ventricular hypertrophy were assessed in the parasternal short axis view and confirmed from parasternal long axis and apical views. The ventricle was divided into four regions: anterior septum, posterior septum, lateral wall, and posterior walls. Wall thickness was measured at the level of the mitral valve and papillary muscles in each of the four myocardial segments. MLVWT was defined as the greatest thickness in each segment. Patterns of hypertrophy were defined in accordance with previously published methods. Left ventricular outflow tract gradient (LVOTG) was calculated from Doppler velocity profile by a modified Bernoulli equation, $\Delta \mathrm{P}=4 \mathrm{~V}^{2}$, where $\Delta \mathrm{P}$ is the instantaneous pressure gradient $(\mathrm{mm} \mathrm{Hg})$ and $\mathrm{V}$ is the measured maximum flow velocity $(\mathrm{m} / \mathrm{s})$.

End points for the survival analysis were as follows:

- Sudden cardiac death: witnessed sudden death with or without documented ventricular fibrillation, death within one hour of new symptoms, or nocturnal death with no antecedent history of worsening symptoms.

- Progressive heart failure death: death preceded by signs and symptoms of heart failure or cardiogenic shock.

- Other cardiovascular death: deaths caused by stroke, pulmonary or systemic embolism, and myocardial infarction.

- Non-cardiovascular death: deaths caused by known noncardiovascular and unknown events.

- Orthotopic heart transplantation.

In patients with an implantable cardioverter-defibrillator (ICD) the first appropriate shock was coded as an outcome in the survival analysis.

\section{Data analysis}

Statistical analysis was performed with SPSS (version 10.0) statistical software (SPSS Inc, Chicago, Illinois, USA). All data are expressed as mean (SD) (range) or frequency (\%). Differences in continuous variables were assessed with Student's $t$ test or $\chi^{2}$ and Fisher's exact test for noncontinuous variables. Survival estimates were calculated by the Kaplan-Meier method and their relation to SI was tested by log rank. Five year survival values are expressed together with their 95\% confidence interval (CI) defined as survival $\pm 1.96 \times$ SE. Cox regression analysis was used to investigate the relation between significant variables and survival. Receiver operating characteristic curves were constructed by plotting sensitivity against ( $1-$ specificity). Values of $\mathrm{p}<0.05$ were considered significant.

\section{RESULTS}

\section{Baseline evaluation}

Table 1 summarises the demographic, clinical, and echocardiographic parameters of the 1080 patients at initial evaluation. HCM was diagnosed after presentation with symptoms in $527(48.8 \%)$ patients and during familial assessment in $268(24.8 \%)$. The diagnosis was an incidental finding in 285 (26.4\%) patients. The reasons for referral to the clinic were clinical management ( $\mathrm{n}=404,37.4 \%)$; risk stratification $(\mathrm{n}=184,17.0 \%)$; family screening $(\mathrm{n}=173,16.0 \%)$; diagnostic clarification $(\mathrm{n}=123,11.4 \%)$; and genetic counselling or referral for second opinion ( $\mathrm{n}=196$, $18.2 \%)$. FS ranged from 9-72\%, mean (SD) $42.6(8.9) \%$ (fig 1). FS was $\leqslant 25 \%$ in $26(2.4 \%)$ patients, aged 49 (14) years (range 18-73 years). Four patients (15.4\%) with SI came from two different families and the other $22(84.6 \%)$ patients were unrelated. Five $(22.7 \%)$ of the 22 unrelated patients had one or more affected family members evaluated as part of the study cohort.

Severe functional limitation (New York Heart Association (NYHA) class $\geqslant$ III) was reported more often in patients with SI than in patients with normal systolic function; however, this difference did not reach significance $(p=0.07)$. SI was associated with an increased history of atrial fibrillation $(p=0.006)$, larger ventricular cavity dimensions $(\mathrm{p}<0.001)$, and larger left atrium $(\mathrm{p}<0.0001)$. No patient with SI had significant resting LVOTG ( $\geqslant 30 \mathrm{~mm} \mathrm{Hg}$ ) compared with $280(26.6 \%)$ patients with normal systolic function $(\mathrm{p}=0.0005)$. The mean MLVWT was lower in patients with SI $(18.2(4.2) \mathrm{mm})$ than in patients with normal FS (20.3 (6.1) mm); however, this did not reach significance $(p=0.07)$. No patient with SI had severe left ventricular hypertrophy $(\geqslant 30 \mathrm{~mm})$ compared with 100 $(9.5 \%)$ patients with normal systolic function.

\section{Survival}

The mean (SD) length of follow up of the 1080 patients was 59 (49) months (range 1-307 months); follow up was complete (to December 2002) for $95.9 \%$ of patients. Forty three $(4.1 \%)$ patients could not be traced; these patients had been seen only once at this institution. During follow up, 108 (10.2\%) patients with normal systolic function died, had an ICD discharge, or underwent cardiac transplantation (sudden death $\mathrm{n}=48$, heart failure related death $\mathrm{n}=11$, cardiac transplantation $\mathrm{n}=6$, other cardiac death $\mathrm{n}=17$, noncardiac death $\mathrm{n}=22$, ICD discharge $\mathrm{n}=7$ ) compared with nine $(34.6 \%)$ patients with SI (sudden death $\mathrm{n}=1$, heart failure $\mathrm{n}=3$, transplantation $\mathrm{n}=2$, non-cardiac death $\mathrm{n}=2$, ICD discharge $\mathrm{n}=1$ ). The five year cumulative survival from sudden death or ICD discharge was 94.9\% (95\% CI $93.2 \%$ to $96.6 \%$ ) in patients with normal systolic function versus $82.2 \%$ (95\% CI $57.6 \%$ to $100 \%$ ) in patients with SI $(\mathrm{p}=0.18)$ (fig 2$)$. The five year cumulative survival rate from heart failure or cardiac transplantation was 98.6\% (95\% CI $97.6 \%$ to $99.5 \%$ ) in patients with preserved systolic function versus $75.6 \%$ (95\% CI $50.5 \%$ to $96.8 \%$ ) in patients with SI $(p<0.0001)$. The five year cumulative survival rate from any cause of death, ICD discharge, or cardiac transplantation was $90.1 \%$ (95\% CI $87.8 \%$ to $92.4 \%$ ) in patients with normal systolic function versus $52.4 \%$ (95\% CI $25.2 \%$ to $79.6 \%)$ in patients with SI $(p<0.0001)$ (fig 3 ).

\section{Results of serial evaluation}

Of the 462 patients (390 families) with normal systolic function who underwent serial echocardiography, 22 (4.8\%) patients ( 12 men, 10 women aged 41 (15) years) developed SI. The yearly incidence of SI was $0.87 \%$ (95\% CI $0.54 \%$ to $1.31 \%)$. The five year probability of developing SI was $2.0 \%$ $(95 \%$ CI $0.3 \%$ to $3.7 \%)$. Table 2 shows the baseline 
Table 1 Baseline characteristics of 1080 patients studied

\begin{tabular}{|c|c|c|c|}
\hline & \multicolumn{2}{|c|}{ FS at initial evaluation } & \multirow[b]{2}{*}{ p Value } \\
\hline & $>\mathbf{2 5} \%$ & $\leqslant 25 \%$ & \\
\hline Number of patients & $1054(97.6 \%)$ & $26(2.4 \%)$ & NA \\
\hline Men/women & $643 / 411$ & $18 / 9$ & 0.7 \\
\hline Age (years) & $42(15)(16-88)$ & 49 (14) (18-73) & 0.03 \\
\hline Age at diagnosis (years) & 38 (16) (3-88) & 38 (19) (5-73) & 0.9 \\
\hline Follow up (months) & 59 (49) (0-307) & $42(40)(0-119)$ & 0.04 \\
\hline VF & $19(1.8 \%)$ & $0(0.0 \%)$ & NA \\
\hline $\mathrm{AF}$ & $129(12.2 \%)$ & $9(34.6 \%)$ & 0.006 \\
\hline Exertional chest pain & $300(28.5 \%)$ & $6(23.1 \%)$ & 0.5 \\
\hline \multicolumn{4}{|l|}{ NYHA class } \\
\hline I & $666(63.2 \%)$ & $13(50.0 \%)$ & 0.2 \\
\hline$\|$ & $359(34.1 \%)$ & $10(38.5 \%)$ & 0.7 \\
\hline III-IV & $29(2.8 \%)$ & $3(11.5 \%)$ & 0.07 \\
\hline Family history of HCM & $464(44.0 \%)$ & $10(38.5 \%)$ & 0.6 \\
\hline Family history of SCD & $313(29.7 \%)$ & $10(38.5 \%)$ & 0.3 \\
\hline Palpitations & $272(25.8 \%)$ & $9(34.6 \%)$ & 0.3 \\
\hline Syncope & $158(15.0 \%)$ & 5 (19.2\%) & 0.6 \\
\hline Abnormal BP response & $264(25.0 \%)$ & $5(19.2 \%)$ & 0.7 \\
\hline Non-sustained VT & $182(17.3 \%)$ & $7(26.9 \%)$ & 0.09 \\
\hline Severe LVH & $100(9.5 \%)$ & 0 & 0.2 \\
\hline Wigle & $4.6(2.7)(0-10)$ & $2.3(2.5)(0-8)$ & $<0.0001$ \\
\hline MLVWT (mm) & $20.3(6.1)(8-49)$ & $18.2(4.2)(13-25)$ & 0.07 \\
\hline \multicolumn{4}{|l|}{ Pattern } \\
\hline $\mathrm{ASH}$ & $674(63.9 \%)$ & $12(46.2 \%)$ & 0.04 \\
\hline Concentric & $301(28.6 \%)$ & $10(38.5 \%)$ & 0.3 \\
\hline Apical & $45(4.3 \%)$ & $2(7.7 \%)$ & 0.3 \\
\hline Other/not measurable & $34(3.2 \%)$ & $2(7.7 \%)$ & NA \\
\hline LVOTG & $280(26.6 \%)$ & 0 & 0.0005 \\
\hline LVEDD $(\mathrm{mm})$ & $43.8(5.8)(24-65)$ & $51.5(10.6)(32-82)$ & 0.001 \\
\hline LVESD (mm) & $24.9(5.6)(10-45)$ & $41.0(9.0)(24-61)$ & $<0.0001$ \\
\hline FS (\%) & $43.1(8.2)(26-72)$ & $20.2(5.2)(9-25)$ & $<0.0001$ \\
\hline LA diameter $(\mathrm{mm})$ & $43.0(7.9)(20-75)$ & $51.3(9.2)(34-73)$ & $<0.0001$ \\
\hline \multicolumn{4}{|c|}{ Medication/procedures during follow up } \\
\hline Amiodarone & $307(29.1 \%)$ & $10(38.5 \%)$ & 0.3 \\
\hline$\beta$ Blocker & $427(40.5 \%)$ & $6(23.1 \%)$ & 0.07 \\
\hline Calcium antagonist & $286(27.1 \%)$ & $3(11.5 \%)$ & 0.8 \\
\hline Disopyramide & $116(11.0 \%)$ & $1(3.8 \%)$ & 0.3 \\
\hline Sotalol & $76(7.2 \%)$ & $2(7.7 \%)$ & 0.7 \\
\hline Diuretic & $195(18.5 \%)$ & $13(50.0 \%)$ & $<0.0001$ \\
\hline ACE inhibitor & $82(7.8 \%)$ & $13(50.0 \%)$ & $<0.0001$ \\
\hline Pacemaker & $95(9.0 \%)$ & $3(11.5 \%)$ & 0.7 \\
\hline $\mathrm{ICD}$ & $53(5.0 \%)$ & $1(3.8 \%)$ & 1 \\
\hline Myectomy/ablation & $41(3.9 \%)$ & 0 & NA \\
\hline \multicolumn{4}{|c|}{$\begin{array}{l}\text { Data are mean (SD (range) or number (\%). } \\
\text { ACE, angiotensin converting enzyme; AF, atrial fibrillation; ASH, symmetrical septal hypertrophy; BP, blood } \\
\text { pressure during exercise; FS, fractional shortening; HCM, hypertrophic cardiomyopathy; ICD, implantable } \\
\text { cardioverter-defibrillator; LA, left atrial; LVEDD, left ventricular end diastolic diameter (mm); LVESD, left ventricula } \\
\text { end systolic diameter; LVH, left ventricular hypertrophy; LVOTG, left ventricular outflow tract gradient } \geqslant 30 \text { mm Hg } \\
\text { MLVWT, maximum left ventricular wall thickness; NA, not applicable; NYHA, New York Heart Association } \\
\text { functional class; SCD, sudden cardiac death; VF, ventricular fibrillation before evaluation; VT, ventricular } \\
\text { tachycardia. }\end{array}$} \\
\hline
\end{tabular}

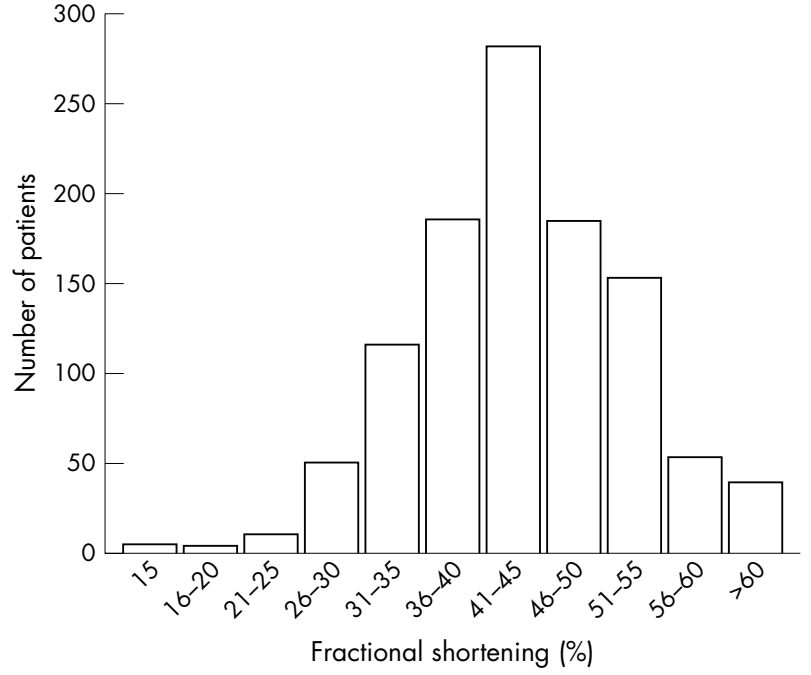

Figure 1 Fractional shortening at initial evaluation. characteristics of patients who developed SI and those with preserved systolic function. Two of the patients who progressed to SI were from one family. One further patient (aged 30 years) who developed SI and subsequently died of heart failure had an affected family member (aged 46 years) who also had SI at initial evaluation in our centre but was followed up elsewhere; she also subsequently died of heart failure. The remaining $19(86.4 \%)$ patients who developed SI were unrelated. Five $(22.7 \%)$ of the 19 unrelated patients had one or more affected family members with normal systolic function evaluated as part of the study cohort.

Follow up duration was longer for patients who developed SI than for patients who maintained normal systolic function (100 (47) months $v 64$ (40) months, $\mathrm{p}=0.007$ ). In patients with preserved systolic function at last follow up small but significant changes in left ventricular morphology occurred. In these patients FS was reduced by a mean of $1.1(8.4) \%$ $(\mathrm{p}=0.007)$ in association with a reduction in MLVWT (from $20.5 \mathrm{~mm}$ to $19.9 \mathrm{~mm}, \mathrm{p}=0.002$ ), increase in cavity size (from $43.6 \mathrm{~mm}$ to $44.4 \mathrm{~mm}, \mathrm{p}=0.01$ for LVEDD and from $24.7 \mathrm{~mm}$ to $25.7 \mathrm{~mm}, \mathrm{p}<0.001$ for LVESD), increase 


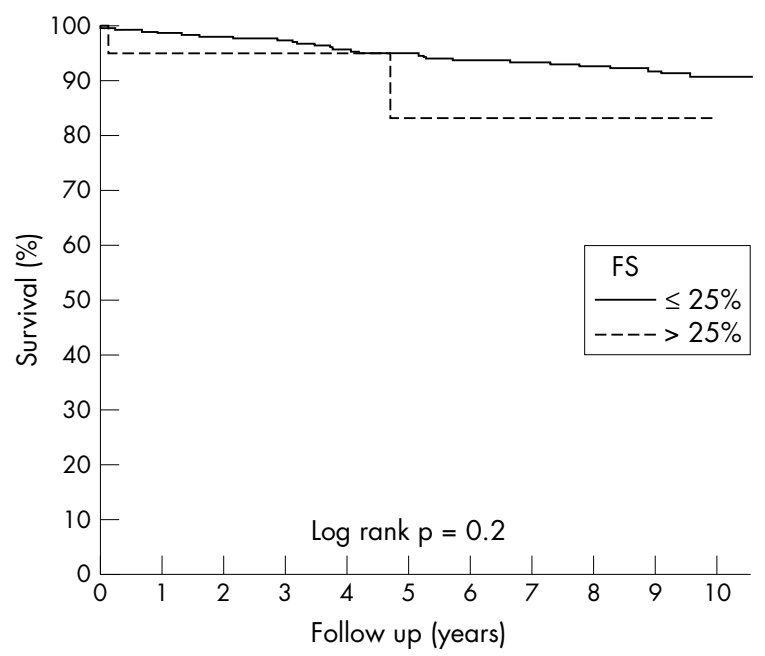

$\begin{array}{lcccc}\text { Number of patients at risk } & & & \\ & 0 \text { year } & 3 \text { years } & 6 \text { years } & 9 \text { years } \\ \text { FS }>25 \% & 1054 & 606 & 348 & 187 \\ \text { FS } \leq 25 \% & 26 & 11 & 4 & 1\end{array}$

Figure 2 Kaplan-Meier estimates of the proportions of patients surviving sudden death or implantable cardioverter-defibrillator (ICD) discharge in relation to systolic function at initial evaluation. FS, fractional shortening.

in left atrial size (from $42.9 \mathrm{~mm}$ to $45.6 \mathrm{~mm}, \mathrm{p}<0.001$ ), and reduction in numbers of patients with significant LVOTG (from $108(24.5 \%)$ to $89(19.3 \%), p=0.06)$. In patients who developed SI there were much larger changes in FS and left ventricular morphology: there was a mean reduction in FS of $15.8(7.8) \%(\mathrm{p}<0.0001)$. This was accompanied by a reduction in MLVWT from $23.4 \mathrm{~mm}$ to $17.5 \mathrm{~mm}$ $(\mathrm{p}<0.0001)$ and an increase in left ventricular cavity dimensions; LVEDD increased from $48.3 \mathrm{~mm}$ to $53.6 \mathrm{~mm}$ $(\mathrm{p}<0.0001)$ and LVESD increased from $30.7 \mathrm{~mm}$ to $42.4 \mathrm{~mm}(\mathrm{p}<0.0001)$. In this group left atrial size also increased from $45.8 \mathrm{~mm}$ to $52.5 \mathrm{~mm}(\mathrm{p}<0.0001)$ and no patient at last follow up had a significant LVOTG.

Of the 22 patients who developed SI during follow up 13 $(59.1 \%)$ died or underwent cardiac transplantation (sudden death $\mathrm{n}=3$, heart failure $\mathrm{n}=5$, transplantation $\mathrm{n}=3$, non-cardiac death $\mathrm{n}=2$ ) compared with $38(8.6 \%)$ patients who maintained normal systolic function (sudden death $\mathrm{n}=16$, heart failure related death $\mathrm{n}=1$, cardiac transplantation $\mathrm{n}=3$, other cardiac death $\mathrm{n}=8$, non-cardiac death $\mathrm{n}=10$ ).

\section{Predictors of progression to SI}

Progression to SI was unrelated to age at initial evaluation or to sex. On initial evaluation syncope $(p=0.001)$, nonsustained ventricular tachycardia $(\mathrm{p}=0.002)$, and an abnormal blood pressure responses to exercise $(p=0.001)$ were more common in patients who progressed to SI (table 2). At initial evaluation the proportion of patients with severe functional limitation (NYHA $\geqslant$ III) was similar in patients who maintained normal systolic function ( $\mathrm{n}=13,2.9 \%)$ and in those who developed SI $(\mathrm{n}=1$, $4.5 \%$ ) during follow up. At last follow up, the proportion of patients with severe limitation was significantly higher in those who developed SI $(\mathrm{n}=9,40.9 \% \vee \mathrm{n}=61,13.8 \%$, $\mathrm{p}=0.001)$.

Patients who developed SI had a greater MLVWT $(\mathrm{p}=0.04)$, increased left ventricular cavity size $(\mathrm{p}<0.0001$ for LVESD and $\mathrm{p}<0.0003$ for LVEDD), and lower FS $(p=0.0002)$ at initial evaluation than patients

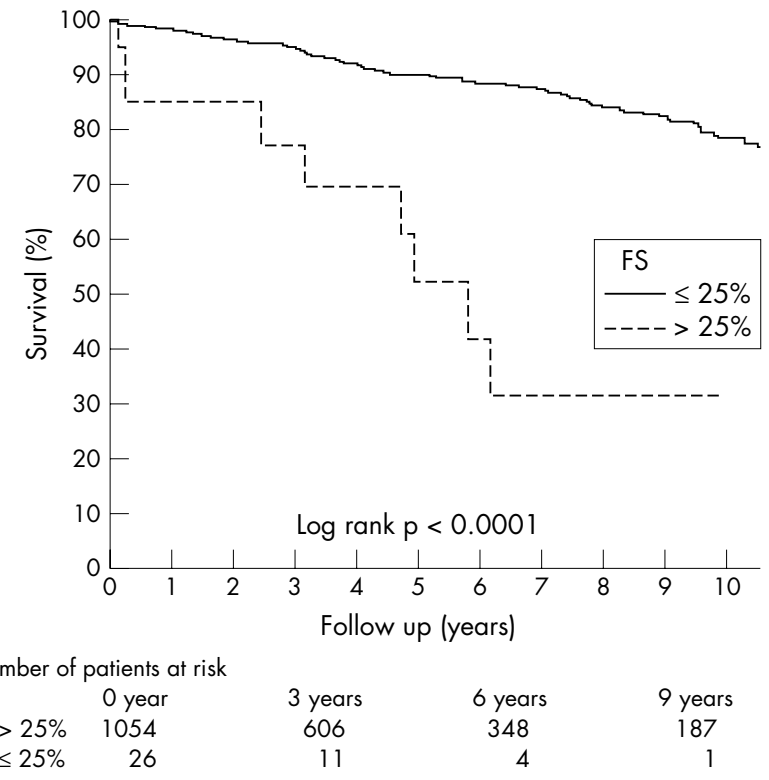

Figure 3 Kaplan-Meier estimates of the proportions of patients surviving death from all causes, ICD discharge, or transplantation in relation to systolic function at initial evaluation.

who maintained normal systolic function (table 2). During follow up there was a greater mean increase in LVESD than in LVEDD (11.7 (8.0) $\mathrm{mm} v 5.3$ (8.3) mm, respectively, $\mathrm{p}<0.0001)$ in patients who developed SI. In multivariate regression analysis based on age, sex, left ventricular wall thickness, and cavity dimensions, baseline LVESD had the strongest correlation with progression to SI. An LVESD $\geqslant 30 \mathrm{~mm}$ predicted progression to SI with a sensitivity of $59.1 \%$, specificity of $81.1 \%$, and accuracy of $80.1 \%$. The odds ratio for developing SI associated with an LVESD $\geqslant 30 \mathrm{~mm}$ was $6.2(95 \%$ CI 2.6 to $15.0, \mathrm{p}<0.001)$.

\section{DISCUSSION}

This study shows that severe SI is an uncommon feature of HCM with an annual incidence of less than $1 \%$. The discrepancy with earlier studies that have reported a much higher prevalence of severe left ventricular SI is probably explained by differences in patient selection. ${ }^{134910}$ For example, fewer than $3 \%$ of patients in this study were in NYHA class III or IV at their initial assessment compared with $70 \%$ in some early studies. ${ }^{11}$

Notwithstanding its rarity, however, progression to SI is associated with deterioration in functional capacity and a substantial risk of death from heart failure or requirement for cardiac transplantation. ${ }^{3}$

\section{Mechanisms of SI}

In dilated or ischaemic cardiomyopathy SI reflects a process of ventricular remodelling caused by changes at the molecular and cellular levels leading to changes in the size, shape, and function of the heart. ${ }^{12}$ These changes include ischaemia, necrosis, apoptosis, increased collagen synthesis, and fibroblast proliferation and are thought to be influenced by haemodynamic alterations, neurohormonal activation, oxidative stress, and cytokines. ${ }^{13-15}$ It is likely that similar mechanisms apply in HCM, in particular ischaemia and progressive myocardial fibrosis. ${ }^{16}{ }^{17}$ A genetic susceptibility to the development of SI in HCM has also been suggested by studies showing a predisposition to systolic dysfunction within some families. However, even within families carrying the same mutation there appears to be a significant degree of 


\begin{tabular}{|c|c|c|c|}
\hline & \multicolumn{2}{|l|}{ FS at last evaluation } & \multirow[b]{2}{*}{ p Value } \\
\hline & $>25 \%$ & $\leqslant 25 \%$ & \\
\hline Number of patients & 440 (95.2\%) & $22(4.8 \%)$ & NA \\
\hline Men/women & $278 / 162$ & $12 / 10$ & 0.4 \\
\hline Age (years) & $41(14)(16-79)$ & 41 (15) (19-71) & 0.8 \\
\hline Age at diagnosis (years) & 36 (15) (3-78) & 35 (17) (11-71) & 0.6 \\
\hline Follow up (months) & $64(40)(12-192)$ & $100(47)(16-193)$ & 0.007 \\
\hline VF & $9(2.0 \%)$ & $1(4.5 \%)$ & NA \\
\hline $\mathrm{AF}$ & $67(15.2 \%)$ & $6(27.3 \%)$ & 0.1 \\
\hline Exertional chest pain & $126(28.6 \%)$ & $10(45.5 \%)$ & 0.07 \\
\hline \multicolumn{4}{|l|}{ NYHA class } \\
\hline 1 & 269 (61.0\%) & $13(59.1 \%)$ & 0.2 \\
\hline$\|$ & $159(36.1 \%)$ & $8(36.4 \%)$ & 1 \\
\hline III-IV & $13(2.9 \%)$ & $1(4.5 \%)$ & NA \\
\hline Family history of SCD & 134 (30.4\%) & $8(36.4 \%)$ & 0.5 \\
\hline Palpitations & $115(26.1 \%)$ & $7(31.8 \%)$ & 0.3 \\
\hline Syncope & $67(15.2 \%)$ & $10(45.5 \%)$ & 0.001 \\
\hline Abnormal BP response & $131(29.7 \%)$ & $15(68.2 \%)$ & 0.001 \\
\hline Non-sustained VT & $91(20.6 \%)$ & $11(50.0 \%)$ & 0.002 \\
\hline Severe LVH & $42(9.6 \%)$ & $4(18.2 \%)$ & 0.3 \\
\hline \multicolumn{4}{|l|}{ Risk factor SD } \\
\hline 0 & $164(37.2 \%)$ & $2(9.1 \%)$ & NA \\
\hline 1 & $165(37.4 \%)$ & $8(36.4 \%)$ & NA \\
\hline 2 & $89(20.2 \%)$ & $6(27.3 \%)$ & NA \\
\hline 3 & $21(4.8 \%)$ & $4(18.2 \%)$ & NA \\
\hline 4 & $1(0.2 \%)$ & $2(9.1 \%)$ & NA \\
\hline 5 & $1(0.2 \%)$ & 0 & $<0.0001$ \\
\hline LVOTG & $108(24.5 \%)$ & $3(13.6 \%)$ & 0.3 \\
\hline Wigle & $4.4(2.6)(0-10)$ & $5.5(2.2)(0-10)$ & 0.09 \\
\hline MLVWT (mm) & $20.5(6.1)(8-43)$ & $23.4(6.0)(14-37)$ & 0.04 \\
\hline $\operatorname{LVEDD}(\mathrm{mm})$ & $43.6(5.9)(28-60)$ & $48.3(6.7)(39-65)$ & 0.0003 \\
\hline LVESD (mm) & $24.7(5.4)(10-43)$ & $30.7(6.5)(20-45)$ & $<0.0001$ \\
\hline $\mathrm{FS}(\%)$ & $43.3(8.0)(26-72)$ & $36.7(7.1)(27-48)$ & 0.0002 \\
\hline LA diameter $(\mathrm{mm})$ & $42.9(8.2)(20-72)$ & $45.8(6.4)(34-57)$ & 0.1 \\
\hline
\end{tabular}

phenotypic heterogeneity between affected family members suggesting that other genetic or environmental factors have a role. More recently evidence has emerged that particular sarcomeric protein mutations affecting $\alpha$ tropomyosin, troponin $\mathrm{T}$, and $\beta$ myosin heavy chain genes may be responsible for either HCM or dilated cardiomyopathy phenotypes. The genetic or clinical factors responsible for this clinical diversity are unknown but differences in the position of the mutation, energy/signalling pathways, or $\mathrm{Ca}^{2+}$ regulation and handling may be involved. ${ }^{18}{ }^{19}$ Mutation data were not available in this study; however, eight patients from four families (two members of each family) had SI at baseline or during follow up. These numbers were two small to examine linkage; however, we could hypothesise that the vulnerability of some patients towards SI may reflect the underlying genotype.

\section{Clinical predictors of SI}

Although progression to systolic dysfunction and symptomatic heart failure was uncommon in this study most patients had some evidence of wall thinning and left ventricular enlargement. This suggests that some degree of remodelling is inevitable in patients with HCM. In the subset of patients who had significant wall thinning during follow up, syncope was the only symptom that was significantly associated with progression to SI. The explanation for this is unclear but many of the mechanisms of syncope in patients with HCM (for example, arrhythmias and abnormal vascular responses) may be caused or exacerbated by progressive myocyte loss and myocardial fibrosis. Supporting evidence for this hypothesis is provided by the association between progression to SI and the presence of both non-sustained ventricular tachycardia and abnormal exercise blood pressure responses at initial evaluation.

\section{Echocardiographic predictors of SI}

The lower FS and increased cavity dimensions at initial evaluation in patients who progressed to SI in this study imply that the pathophysiological changes that lead to SI were already underway in these patients. The greater MLVWT at initial evaluation in patients who progressed to SI suggests that this cohort is particularly vulnerable to remodelling. Although the reason for this is unknown we postulate that patients with increasingly severe left ventricular hypertrophy may be more prone to subendocardial ischaemia as well as haemodynamic and neurohormonal changes that may influence the remodelling process. On multivariate regression analysis, LVESD had the strongest correlation with progression to SI; however, the sensitivity, specificity, and positive predictive accuracy of LVESD for predicting progression to SI were low.

\section{Limitations}

One of the main limitations of our study was in the definition of SI-that is, FS $\leqslant 25 \%$. FS of $\leqslant 25 \%$, however, seemed to identify patients who developed progressive heart failure and has been used in previous HCM studies as well as in other conditions such as dilated cardiomyopathy. Furthermore it is a reliable measurement to compare echocardiograms performed with different machines or technology over a long period of time. However, we acknowledge that, as many patients with HCM have hyperdynamic systolic function, this conventional cut off may have been too low leading to an underestimate of SI. Systolic function was assessed only at rest. Recently, systolic dysfunction and regional wall motion abnormalities have been detected during exercise and dobutamine stress in patients with HCM and normal resting left ventricular systolic function. ${ }^{20}$ In addition, recent studies with other technologies such as three dimensional 
echocardiography and cardiovascular magnetic resonance have reported a range of wall motion abnormalities in HCM including abnormalities in circumferential shortening and rotational components of heart wall motion. At present, however, only small numbers of patients have been studied and these techniques are generally restricted to a few research centres and are not yet of wide scale practical use. The clinical application of these various abnormalities is unknown. ${ }^{21-25}$

Another limitation was that a proportion of the original study population did not undergo serial evaluation because they were followed up at their own centres. Nevertheless, to our knowledge this is the largest consecutive series describing serial echocardiographic changes in HCM to examine the incidence and natural history of SI. Lastly, all patients with documented coronary artery disease were excluded from this study. However, only patients with typical chest pains or risk factors for coronary artery disease underwent coronary arteriography ( $23 \%$ of the patients who progressed to SI); it is therefore possible that some patients with coronary artery disease were missed. If this was the case, however, and such patients were excluded, the incidence of SI in patients with HCM and normal coronary arteries would have been even lower than reported.

\section{Conclusions}

SI is a rare complication of HCM but when present is associated with a poor outcome.

\section{ACKNOWLEDGEMENTS}

Dr Thaman, Dr Sachdev, and Professor McKenna were supported by the British Heart Foundation, Dr Murphy by the Irish Heart Foundation/Novartis, and Dr Gimeno by the Cardiovascular Research Foundation (Murcia, Spain).

\section{Authors' affiliations}

R Thaman, J R Gimeno, R T Murphy, T Kubo, B Sachdev, J Mogensen, P M Elliott, W J McKenna, The Heart Hospital, University College London, London, UK

\section{REFERENCES}

1 Spirito $\mathrm{P}$, Maron BJ, Bonow RO, et al. Occurrence and significance of progressive left ventricular wall thinning and relative cavity dilatation in hypertrophic cardiomyopathy. Am J Cardiol 1987;60:123-9.

2 Hina K, Kusachi S, Iwasaki K, et al. Progression of left ventricular enlargement in patients with hypertrophic cardiomyopathy: incidence and prognostic value. Clin Cardiol 1993;16:403-7.

3 Shirani J, Maron BJ, Cannon RO III, et al. Clinicopathologic features of hypertrophic cardiomyopathy managed by cardiac transplantation. Am J Cardiol 1993;72:434-40.

4 Suwa M, Hirota Y, Nakayama Y, et al. [Natural course of hypertrophic cardiomyopathy: clinical, hemodynamic and echocardiographic features in the end stage]. J Cardiol Suppl 1987;16:65-78.
5 Richardson P, McKenna W, Bristow M, et al. Report of the 1995 World Health Organization/International Society and Federation of Cardiology task force on the definition and classification of cardiomyopathies. Circulation 1996;93:841-2.

6 McKenna WJ, Spirito P, Desnos $M$, et al. Experience from clinical genetics in hypertrophic cardiomyopathy: proposal for new diagnostic criteria in adult members of affected families. Heart 1997;77:130-2.

7 Elliott PM, Poloniecki J, Dickie S, et al. Sudden death in hypertrophic cardiomyopathy: identification of high risk patients. J Am Coll Cardiol 2000;36:2212-8

8 Elliott PM, Gimeno B Jr, Mahon NG, et al. Relation between severity of leftventricular hypertrophy and prognosis in patients with hypertrophic cardiomyopathy. Lancet 2001;357:420-4.

9 Maron BJ, Lipson LC, Roberts WC, et al. "Malignant" hypertrophic cardiomyopathy: identification of a subgroup of families with unusually frequent premature death. Am J Cardiol 1978;41:1133-40.

10 Fujiwara H, Onodera T, Tanaka M, et al. Progression from hypertrophic obstructive cardiomyopathy to typical dilated cardiomyopathy-like features in the end stage. Jpn Circ J 1984;48:1210-4.

11 Braunwald E, Lambrew CT, Rockoff SD, et al. Idiopathic hypertrophic subaortic stenosis: a description of the disease based upon an analysis of 64 patients. Circulation 1964:30(suppl IV):3-119.

12 Pfeffer MA, Braunwald E. Ventricular remodeling after myocardial infarction: experimental observations and clinical implications. Circulation 1990;81:1161-72

13 Cohn JN, Ferrari R, Sharpe N. Cardiac remodeling: concepts and clinical implications: a consensus paper from an international forum on cardiac remodeling. Behalf of an international forum on cardiac remodeling. J Am Coll Cardiol 2000;35:569-82.

14 Cannon RO III, Rosing DR, Maron BJ, et al. Myocardial ischemia in patients with hypertrophic cardiomyopathy: contribution of inadequate vasodilator reserve and elevated left ventricular filling pressures. Circulation 1985:71:234-43.

15 Narula J, Haider N, Virmani R, et al. Apoptosis in myocytes in end-stage heart failure. N Engl J Med 1996;335:1182-9.

16 Varnava AM, Elliott PM, Sharma S, et al. Hypertrophic cardiomyopathy: the interrelation of disarray, fibrosis, and small vessel disease. Heart 2000;84:476-82

17 Ino T, Nishimoto K, Okubo M, et al. Apoptosis as a possible cause of wall thinning in end-stage hypertrophic cardiomyopathy. Am J Cardiol 1997;79:1137-41.

18 Yamauchi-Takihara K, Nakajima-Taniguchi C, Matsui H, et al. Clinical implications of hypertrophic cardiomyopathy associated with mutations in the alpha-tropomyosin gene. Heart 1996;76:63-5.

19 Arad M, Seidman JG, Seidman CE. Phenotypic diversity in hypertrophic cardiomyopathy. Hum Mol Genet 2002;11:2499-506.

20 Okeie K, Shimizu M, Yoshio $H$, et al. Left ventricular systolic dysfunction during exercise and dobutamine stress in patients with hypertrophic cardiomyopathy. J Am Coll Cardiol 2000;36:856-63.

21 Mishiro Y, Oki T, luchi A, et al. Regional left ventricular myocardial contraction abnormalities and asynchrony in patients with hypertrophic cardiomyopathy evaluated by magnetic resonance spatial modulation of magnetization myocardial tagging. Jpn Circ J 1999:63:442-6.

22 Devlin AM, Moore NR, Ostman-Smith I. A comparison of MRI and echocardiography in hypertrophic cardiomyopathy. Br J Radiol 1999;72:258-64

23 Frielingsdorf J, Franke A, Kuhl HP, et al. Evaluation of regional systolic function in hypertrophic cardiomyopathy and hypertensive heart disease: a three-dimensional echocardiographic study. J Am Soc Echocardiogr $1998 ; 11: 778-86$

24 Maier SE, Fischer SE, McKinnon GC, et al. Evaluation of left ventricular segmental wall motion in hypertrophic cardiomyopathy with myocardial tagging. Circulation 1992:86:1919-28.

25 Scheffknecht BH, Bonow RO, Dwyer AJ, et al. Functional assessment of left ventricular ejection dynamics by cine-magnetic resonance imaging in hypertrophic cardiomyopathy. Am J Cardiol 1994;73:981-4 